\title{
The Flying Machine from an Engineering Standpoint-II
}

\section{A Review of Recent Progress}

By Frederick William Lanchester, M. Inst., C. E.

Continued from Scientific American Supplement No. 2014, Page 91, August 8, 1914

REFERKING to Fig. $7 \mathrm{a}$, it may be observed that the character of the pitching-moment curve depends primarily upon the form of the aerofoil, the position of the center of gravity, and the effective area of the tailmember. By altering the angle of the tail-plane (or by altering its effective angle by moving the fiap known as the elevator) the datum line of Fig. $7 a$ is in effect raised or lowered, but the form of the curve itself is not materially changed. It is evident, therefore, that a given machine may be catastrophically stable within certain limits of the adjustment of its elevator; that is to say, referring to Fig. $7 a$, it will be seen that the datum line may either cut the curve once or three times; the range of adjustment of the elevator that re sults in cutting the curve once leaves the machine catastrophically stable; but when the elevator is adjusted so that the datum ine cuts the curve three times the machine is catastrophically unstable. In such a case as that shown by the dotted datum line in Fig. $7 a$, in which the machine is catastrophically stable, the form of the pitching-moment curve is still open to objection. Not only is it

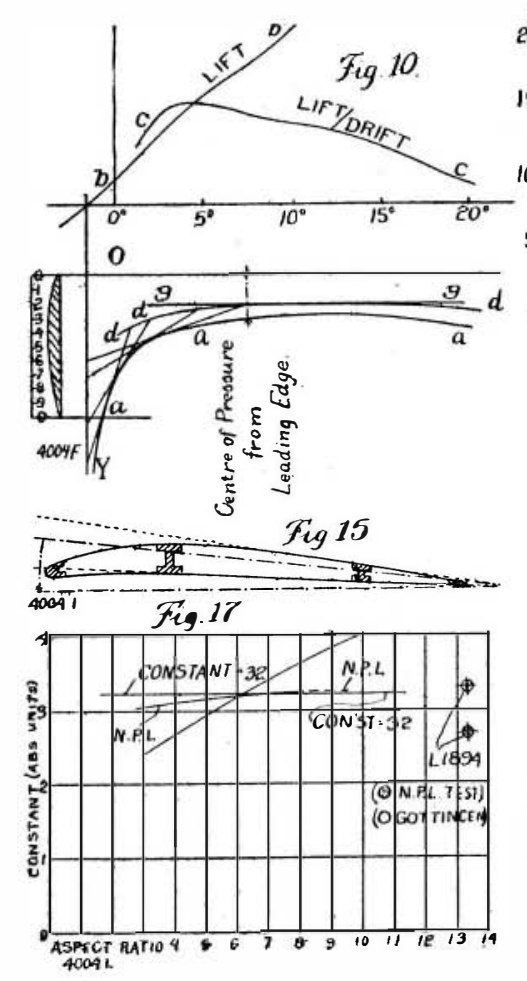

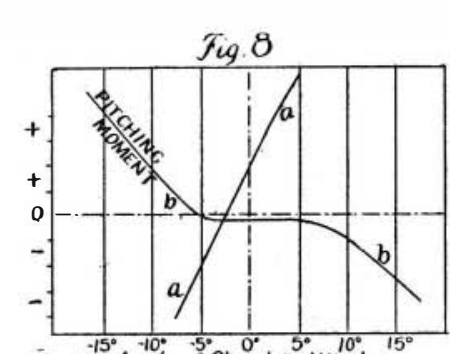

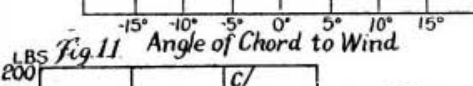

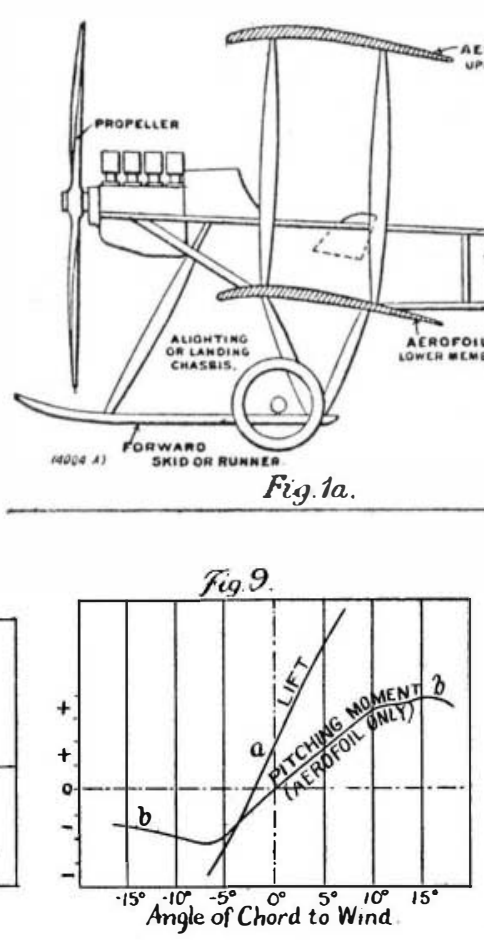

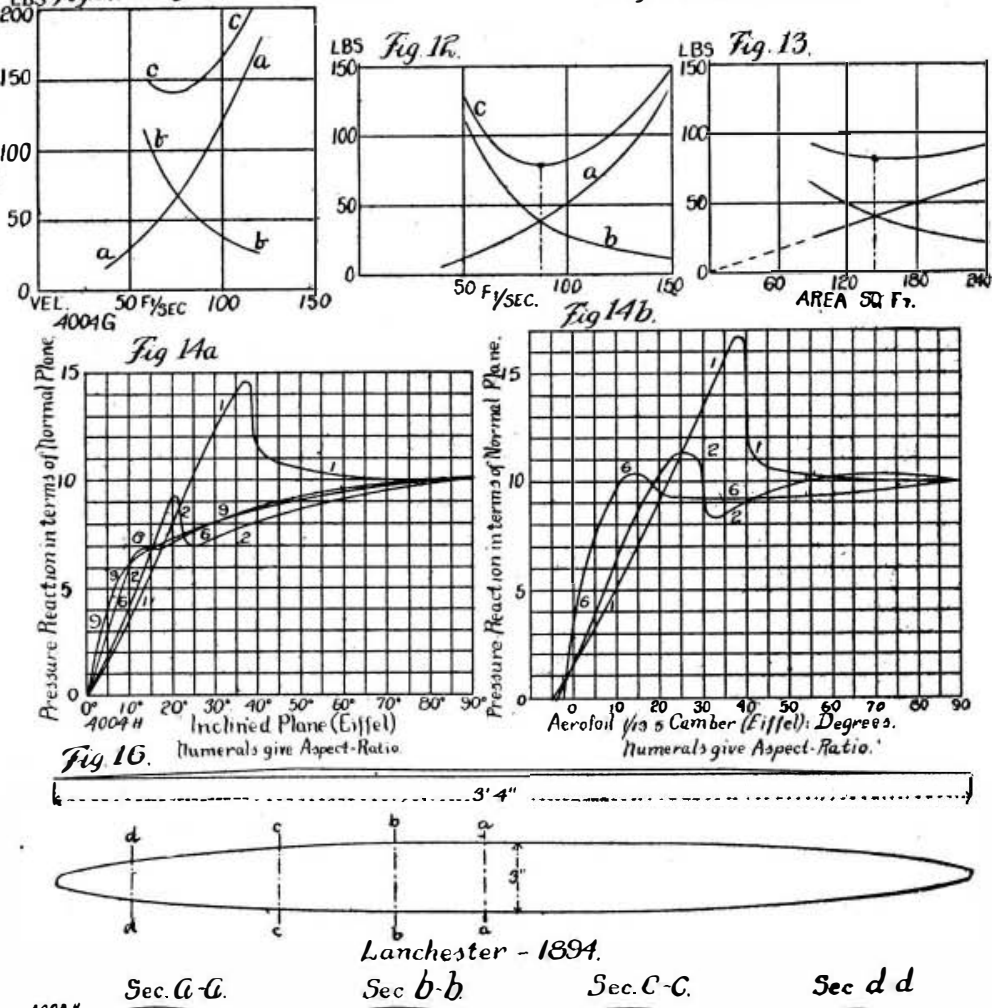

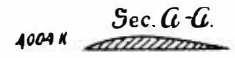

always possible for the pilot to bring about catastrophic instability by an otherwise well-intentioned movement of his elevator, but the restoring couple for pitching beyond a small amplitude ceases to follow even approximately the straight-line law, a fact that inevitably imperils the fiight-path stability. Even when, as illustrated in Fig. 8, the pitching-moment curve $b b$ never passes the horizontal, and so catastrophic instability is no longer to be feared, the conditions are not satisfactory, since there may be a considerable change of attitude of the machine without giving rise to any commensurate restoring couple.

The undesirable kink in the pitching-moment curve, shown in Figs. $7 a, 7 b$, and 8 , is due to the movement of the center of pressure of the aerofoil itself in relation to the position of the center of gravity. The tail plane alone will give a pitching-moment curve of the type illustrated in Fig. 6, but the fore-and-aft change of position of the center of pressure of the aerofoil, at different angles of attack, gives rise to a pitching moment curve whose exact character depends upon the position of the center of gravity. Should this correspond to a positively loaded tail, a curve of the type $b b$, Fig. 9, will result; this, superposed on the tail component, imparts to the pitching-moment curve of the complete machine the kink shown in Fig. $7 a$.

* The James Forrest lecture, delivered before the Institution of Civil Engineers on May 5th. Compare also the same Scientific AMERICAN SUPPLEMENT, February 14 th, 1914, p. 98.
In order definitely to make sure of a satisfactory pitching-moment curve for the complete machine, the pitching-moment curve of the aerofoil alone should at no point exhibit an inverse trend. To achieve this it is necessary to bring the center of gravity appreciably in front of the most forward position of the center of pressure of the aerofoil, so that the tail-plane will under all conditions carry a slight negative load. Taking it as a basis that at the worst point the pitching-moment curve for the aerofoil alone shall be horizontal (the form of curve shown in Fig. 8), the geometrical construction given in Fig. 10 may be employed to give a suitable location to the center of gravity; here the locus of the center of pressure (as experimentally determined) is given by the line aaa, the pressure-reaction curve is shown by the line $b b b$, the dynamic zero being on the line $O Y$. A number of tangents to the pitching-momen curve are drawn at random from points on the axis $O Y$, and are produced a distance equal to their own length beyond the point of contact, the extremities of these tangents defining a curve ddd. Draw gg tangent to $d d d$, then the center of gravity should be situated on, or forward of, the line $g g$. The location of the cente of gravity on this line gives a pitching-moment curve for the aerofoil alone, whose point of infiection is hor at a normal speed corresponding to the maximum at a normal speed corresponding to the maximum
lift/drift ratio of the aerofoil (curve $c c$ ), the center of gravity in this particular case is one eighth of the chord length in advance of the center of pressure. Assuming the tail length equal to three times the chord (as in the
"B.E. 2" type of the Royal Air-Craft Factory, whose outline elevation forms Fig. 1a) this is equivalent to a negative load on the tail equal to 0.04 ( 4 per cent) of the weight of the machine.' A machine so ballasted may be regarded as absolutely secure from catastrophic instability, and as having a pitching-moment curve of an adequate character.

In connection with the present subject it is worthy of remark that in a well-designed aerofoil the most forward position of the center of pressure is never far removed from the point of maximum lift/drift ratio $;^{10}$ this fact is of importance, inasmuch as it permits a considerable range of movement round about the attitude of normal fiight without introducing grave irregularities in the pitching-moment curve. Were it not for this the required conditions might frequently be far more difficult of fulfilment than is actually the case. 3. T'he Laws of Resistanct.-Having established the general character of the airway, or track on which the fiying machine is sustained, we pass directly to the consideration of the law of resistance, as determining the coefficient of traction, on which depends the power expenditure. It is customary, and it is correct, to regard the resistance encountered by a machine in flight as made up of two parts: first, the direct resistance, which varies approximately ${ }^{11}$ as $V^{2}$, namely, that form of resistance common to flying machines, dirigibles, motorcars, ships, etc.; in other words, the ordinary resistance experienced by any vessel or body in its passage through a fiuid; and, secondly, the fiight resistance proper, which follows an entirely different régime. So far as the pilot or aviator himself is concerned, all the direct resistances may be regarded as of the same kind and grouped together, namely, the sum of the eddy-making and skin-frictional resistances due to the fuselage, the alighting chassis, and the various struts, stays, and spars, whether belonging to the body of the machine or aerofoil; also the engine resistance (if exposed), the radiator, and the frictionally exposed surfaces of the rudders, fins (vertical surface), and of the aerofoil itself. Resistance from all these causes varies approximately as $V^{2}$, and so can be represented by an equivalent normal plane, and this equivalent normal plane is one of the resistance constants of any given machine; it may be represented by a graph aa, Fig. 11-a portion of a parabola-covering the range of speed of which the machine is capable.

From the point of view of the pilot, the aerodynamic resistance $b b$, which goes to make up the total $c c$ (Fis. 11), follows, within limits, the inverse square law,

${ }^{\theta} \mathrm{A}$ similar conclusion was reached by the author some eight years ago, based on an entirely different method of investigation. For model expcriment a negatively loaded tail was found to be advantageous; the figure $\mathbf{0 . 0 3 5}$ is given in "Aerial
Flight," vol. ii, p. 335. It is desirable to work with a less proportion of negative load from the point of view of keeping the resistance low; evidently the matter is one for compro. mise.

${ }^{10}$ This is not in the nature of a coincidence; a well-designed acrofoil at its attitude of least resistance meets and leaves the stream lines representing the relative air flow (in the region of its mid-section) conformably. Under these concause any abrupt change in the aerodynamic system. expedients as flattening the extremities and giving a reflex curve to the trailing edge are also found to be of service. ${ }^{11}$ The $V^{2}$ latw, it would appear, in no case exactly represents the actual facts; the departures from this law crop up in various and sometimes most unexpected directions. In the case of resistance due to skin-friction, sufficient data exist to enable the degree of departure from the law to be computed; in other cases, as for example, in the pressure reaction experienced by an inclined plane or aerofoil, departures of a
different kind have been demonstrated, and are being graddifferent kind have been demonstrated, and are being grad-
ually elucidated by experimental investigation. In spite of ually elucidated by experimental investigation. In spite of
these shortcomings, the foundation theory of flight is to-day, these shortcomings, the foundation theory of flight is
and probably will continue to be, based on the $\boldsymbol{V}^{2}$ law. 
namely, varies as $k / V^{2}$, where $k$ is a constant determined by the design of the aerofoil; there is a critical angle which defines the low velocity limit of this law, and at best the inverse square law is but an approximation; it is the correct law to assume for an undefined form of aerofoil, bit every. individual design has its own particular manner of variation, which must be ascertained by experiment. The experimental determinations for any aerofoil include, with the aerodynamic resistance, the skin-frictional, and a certain amount of other inseparable direct resistance, so that if experimental values are taken, these resistances should not be again included in the computation of the equivalent normal plane.

From the point of view of the designer, things wear a somewhat different aspect, and a sharp line has to be drawn between two different classes of direct resistance. In the first place, there is the body resistance, which is taken to include the resistance of all those parts, such as fuselage, alighting gear, etc., which is independent of the design of the aerofoil. In the second place, there is the direct aerofoil resistance, including the skin-friction and strut and stay resistances, which are variables depending upon the area and span, and otherwise upon the design of the aerofoil itself. The designer can, by sufficiently extending the aerofoil, reduce the aerodynamic resistance (as shown by Langley) to as low a value as he please, within the limit prescribed by the question of the added weight; but this reduction in the aerodynamic resistance is accompanied by an increase of skin-frictional and other direct aerofoil resistances, so that for any given machine and designed velocity

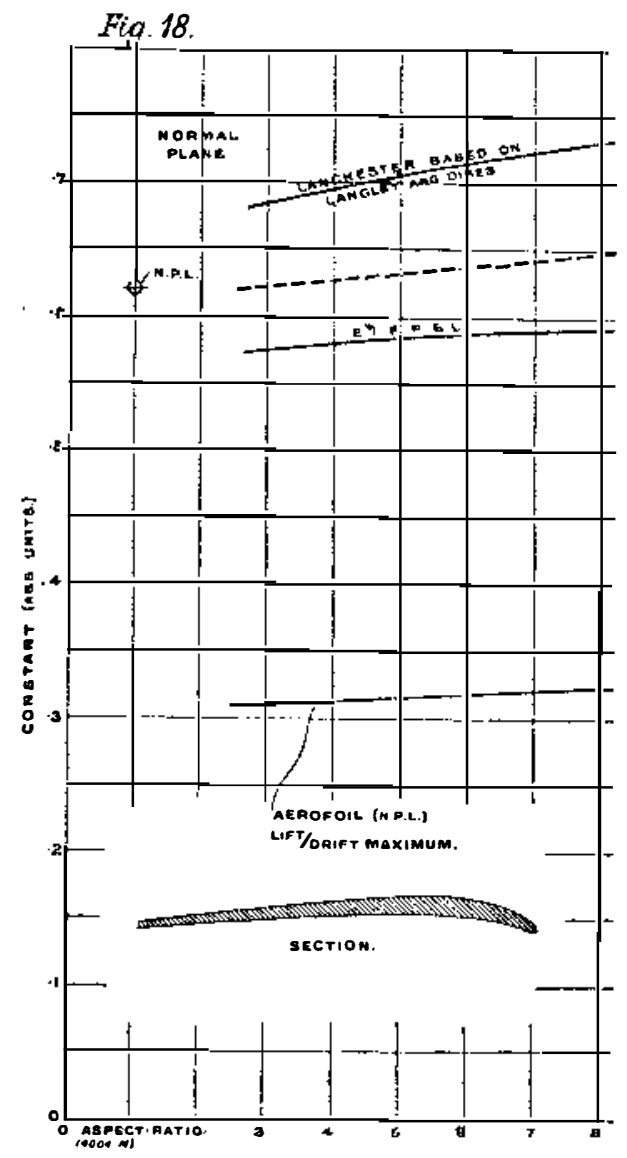

there is an extent of aerofoil beyond which it does not pay to go; there is definitely a design of least resistance.

I have shown that, treating the matter from the broad standpoint of general theory, the condition of least resistance is reached when the aerodynamic and direct resistance of the aerofoil are equal to one another. $^{12}$ This is illustrated by Fig. 12, in which (as in Fig. 11) a represents the graph of the direct resistance $\left(R \infty V^{2}\right)$, and $b b$ that of aerodynamic resistance $\left(R \infty 1 / V^{2}\right)$, and $c c$ is the total (ordinates $=$ resistance,

TABLE IV.-Values of $\beta$ (Angle of Trail) for Least Resistance.

\begin{tabular}{|c|c|c|c|}
\hline Aspect Ratio. & $\xi=0.20$ & $\xi=0.015$. & $\xi=0.010$. \\
\hline & & & \\
\hline 3 & $0.189=10.8$ & $0.163=9.3$ & $0.133=7.6$ \\
\hline 4 & $0.196=11.2$ & $0.169=9.7$ & $0.138=7.9$ \\
\hline 5 & $0.202=11.6$ & $0.174=10.0$ & $0.142=8.1$ \\
\hline 6 & $0.206=11.8$ & $0.178=10.2$ & $0.145=8.3$ \\
\hline 7 & $0.212=12.15$ & $0.183=10.5$ & $0.149=8.5$ \\
\hline 8 & $0.218=12.5$ & $0.189=10.8$ & $0.145=8$ \\
\hline
\end{tabular}

abscissæ = velocity). In Fig. 13 a similar result is shown in which the plotting is given for constant

12 "Aerial Flight," vol. i, ch. vii.

${ }^{13}$ It is not easy to define the angle of trail of an aerofoil when the section is one of considerable body; clearly it is probably more nearly approximating to the former, as shown by the dotted line in Fig. 15. velocity (abscissie = area), as representing more literally the problem as presented to the desioner.

The general theory on which the foregoing result is based depends upon and is subject to the limitations of the $1 / V^{2}$ law of aerodynamic resistance. This law corresponds to the straight-line law as correlating pressure and angle, and is a close approximation between useful limits, but breaks down at a certain critical maximum angle (depending mainly upon the aspect ratio), as shown in the examples given in Figs. 14a and 14b. The square plane follows a straight-line law up to about 30 degrees, in the plane of aspect ratio $=6$; the limit is about 12 degrees, the breakdown of the law at these limiting angles puts a very definite limit to fiying at low speed.

TABle V.--Pterygoid Aerofril.

Load (pounds) per Square Foot for Least Resistance.

Flight

Values of Aspect Ratio.

$$
\begin{gathered}
\text { Feet } \\
\text { per }
\end{gathered}
$$

per$$
3
$$

5
10
15

$\begin{array}{lllllllll}10 & 0.017 & 0.018 & 0.020 & 0.022 & 0.023 & 0.025\end{array}$

\begin{tabular}{lllllllll}
15 & 0.152 & 0.169 & 0.186 & 0.089 & 0.094 & 0.101 \\
\hline & 0.270 & 0.200 & 0.213 & $\mathbf{0 . 2 2 8}$
\end{tabular}

\begin{tabular}{lllll|llll}
25 & 0.2390 & 0.300 & $\mathbf{0 . 3 3 0}$ & $\mathbf{0 . 3 5 5}$ & $\mathbf{0 . 3 7 9}$ & $\mathbf{0 . 4 0 5}$ \\
\hline & 0.390 & 0.433 & $\mathbf{0 . 4 7 5}$ & 0.511 & 0.545 & 0.582
\end{tabular}

$\begin{array}{lllllllll}30 & 0.610 & 0.676 & 0.743 & 0.800 & 0.852 & 0.911\end{array}$

$\begin{array}{llllllll}35 & 0.830 & 0.920 & 1.01 & 1.08 & 1.16 & 1.24 \\ 40 & 1.08 & 1.20 & 1.32 & 1.42 & 1.51 & 1.62\end{array}$

$\begin{array}{lllllll}40 & 1.08 & 1.20 & 1.32 & 1.42 & 1.51 & 1.62 \\ 50 & 1.69 & 1.88 & 2.06 & 2.22 & 2.37 & 2.53\end{array}$

\begin{tabular}{llllll|l|l}
60 & 2.44 & 2.70 & 2.97 & 3.20 & 3.40 & 3.64 \\
$\mathbf{7 0}$ & 3.32 & 3.68 & $\mathbf{4 . 0 5}$ & $\mathbf{4 . 3 5}$ & $\mathbf{4 . 6 4}$ & $\mathbf{4 . 9 6}$
\end{tabular}

\begin{tabular}{lllll|l|lll}
80 & 4.33 & 4.88 & $\mathbf{4 . 0 5}$ & $\mathbf{4 . 3 5}$ & $\mathbf{4 . 6 4}$ & $\mathbf{4 . 9 6}$ \\
$\mathbf{8}$ & $\mathbf{5} 30$ & $\mathbf{5 . 7 0}$ & $\mathbf{6 . 0 7}$ & $\mathbf{6 . 4 7}$
\end{tabular}

\begin{tabular}{|l|l|l|l|l|l|l|}
\hline 0.012 & 0.013 & 0.014 & 0.015 & 0 & 0.1165 & $0.01 \times$ \\
\hline & 0.047 & 0.053 & 0.058 & 0.063 & 0.066 & 0.071
\end{tabular}

\begin{tabular}{ll|l|l|l|l|l|l}
0.047 & 0.053 & 0.014 & 0.015 & 0.010 & $0.01 \times$ \\
0.107 & 0.119 & 0.131 & 0.142 & 0.150 & 0.161
\end{tabular}

$\begin{array}{llllll:l}0.107 & 0.119 & 0.131 & 0.142 & 0.150 & 0.161 \\ 0.190 & 0.211 & 0.234 & 0.253 & 0.267 & 0.287\end{array}$

$\begin{array}{lllllll}0.298 & 0.331 & 0.366 & 0.396 & 0.418 & \mathbf{0 . 4 5 0} \\ \mathbf{0 . 4 2 7} & \mathbf{0 . 4 7 5} & \mathbf{0 . 5 2 6} & \mathbf{0 . 5 7 0} & \mathbf{0 . 6 0 1} & \mathbf{0 . 6 4 5}\end{array}$

$\begin{array}{llllllll}0.582 & 0.647 & 0.717 & 0.777 & 0.820 & 0.880\end{array}$

\begin{tabular}{ll|lllll}
0.760 & 0.845 & 0.935 & 1.01 & 1.07 & 1.15 \\
1.18 & 1.32 & 1.46 & 1.58 & 1.67 & 1.79
\end{tabular}

\begin{tabular}{ll|lll|ll}
1.71 & 1.90 & 2.10 & 2.28 & 2.30 & 2.58 \\
2.32 & 2.58 & 2.86 & 3.10 & 3.27 & 3.51
\end{tabular}

\begin{tabular}{ll|lllll}
3.04 & 3.58 & 3.86 & 3.05 & .3 .97 & 3.51
\end{tabular}

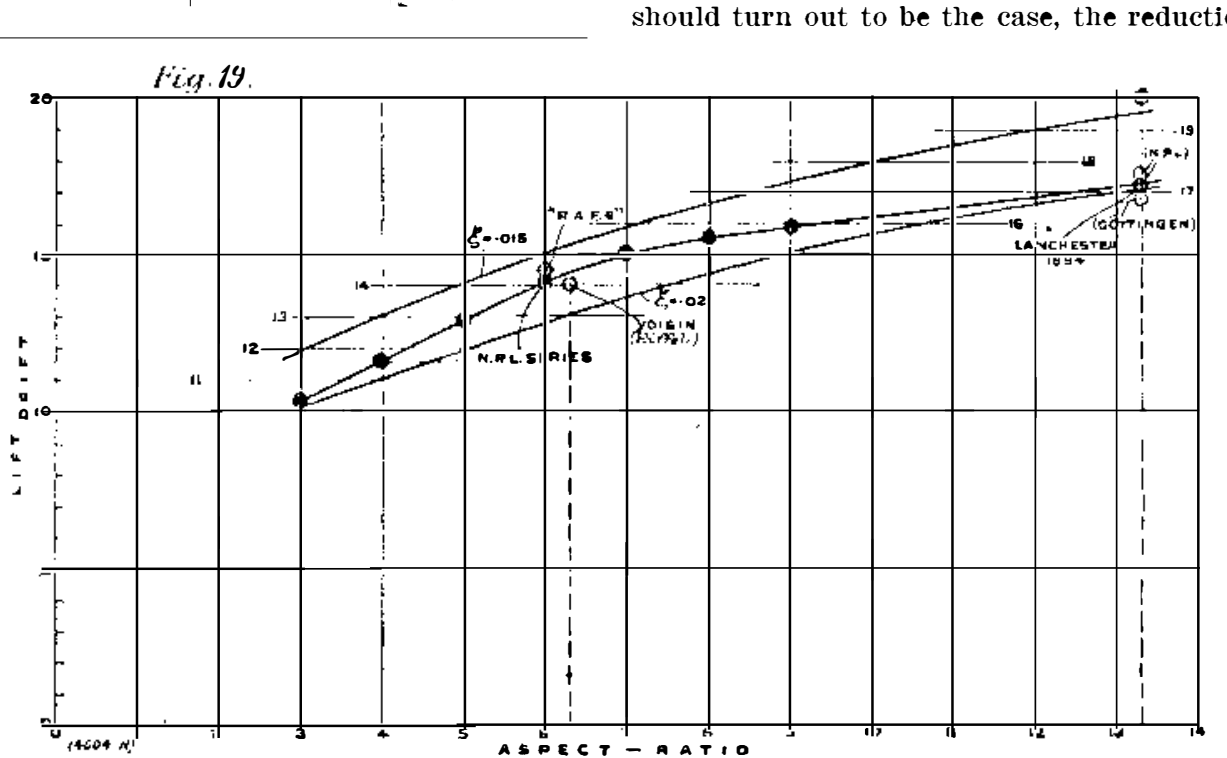

I have demonstrated that the condition of least resistance implies, for an aerofoil of any given aspect ratio, a definite value of the angle of trail, ${ }^{13} \beta$, Fig. 15 the chord angle, except where a plane lamina is used, is an accidental quantity, and not, as frequently supposed, one of fundamental importance; calculated values of trail-angle $\beta$ for least resistance are given in Table IV. Thus any aerofoil properly designed for least resistance for any given velocity of fiight will be correctly designed for every other velocity provided that its load per unit area be varied as the square of the fiight velocity.

It thus becomes possible to prepare tables of meanpressure values proper to least resistance for different fiight velocities and different values of aspect ratio (Table V). Tables IV and V are reproduced from my "Aerial Flight," vol. i, pages 261,262 , and 271 , the variable factors in addition to the fiight speed being the aspect ratio, which is here shown as tabulated for values from 3 to 8 , and the coefficient of skin friction, values of which are taken from 0.01 to 0.02 doublesurface coefficient. These values for skin friction are on the high side, but as an actual fact the values given do fairly represent the total direct resistance that in practice depends upon the area of the foil, and which requires to be included in the useful application of the theory; the higher values, generally speaking, represent more closely biplane conditions, and the lower values are more applicable in the case of the monoplane.

It would appear from recent experiment that my conclusions, as given in Tables IV and V, though in the main correct, require revision; at least in a quantita- tive sense. Thus plotting values of the pressure constant, as derived from 'Table $\mathbf{V}$, for different values of aspect ratio, and as determined for the condition of least resistance (maximum lift/drift) by the National Physcal Laboratory, Fig. 17, we find the two in perfect agreement for aspect ratio $=6$; we also find that both graphs slope in the same direction, namely, they give a higher pressure constant as appropriate to higher aspect ratio; we do not, however, find justification for the extent of the difference as given in my table; the National Physical Laboratory curve gives the effect as very slight indeed-in fact, almost negligible; the pressure constant for the aerofoil tested might be assumed as 0.32 for all values of aspect ratio without serious error. ${ }^{14}$

In Fig. 18, the National Physical Laboratory curve from Fig. 17 has been plotted for comparison with the curve of the normal plane. It is well known that the pressure constant of the normal plane is greater for planes of elongate form; the normal plane curves given in Fig. 18 are based on the determinations of Langley and Dines, as given in "Aerial Flight" (the upper curve); and the more recent determinations of $\mathrm{Mr}$. Eiffel, the values according to this authority being very much lower. On the left, on the line aspect ratio $=1$, we have the value for the square plane as determined by the National Physical Laboratory, and a curve is shown (dotted) directed toward this point as being the nearest we can at present do toward a representation of the truth.

The relation of the normal plane curve to the Niltional Physical Laboratory curve aforesaid is most suggestive; it happens that the values of the constants are almost exactly in the relation of two to one; this is probably a mere coincidence; a more important fact is that the increase of the pressure constant of least resistance (touching changes of aspect ratio) for the aerofoil is almost exactly proportional to the ordinary pressure increase in the case of variations of proportion in the normal plane. This suggests that the increase in the two cases is due to the same primary cause; also that the coefficient of camber proper to least resistance is a quantity independent of the aspect ratio. If this should turn out to be the case, the reduction of the re- sistance for aerofoils of high aspect ratio may be re garded as due entirely to the fact that, where the cyclic component is stronger, the dip of the leading edge can be increased at the expense of that of the trail; that is to say, the chord angle may be diminished with higher aspect ratio, and with it the trail angle will be also diminished. This is contrary to the tabulated results of Table IV; if true, it must lead to the reconsideration of some of the assumptions on which I based $\mathrm{my}$ theory, or at least in the revision of some of the values of my constants.

In spite of the evidence, it is by no means certain that the matter is quite as simple as it appears. It is to be observed that any investigation to determine the effect of aspect ratio must of necessity involve a very complex experimental campaign, not merely a set of determinations with some half dozen or so models sawn off to length from a piece of Blériot or de Havilland "molding"; this is exactly what was done in the experi-

${ }^{14}$ The series of observations from which the curve (NPL) in Fig. 17 was plotted are those given in Advisory Committe Report, 1911-12, Memorandum 60, \& vi, Plate III; the sec

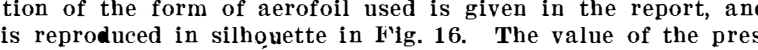
sure constant (at maximum lift/drift) evidently varies con sure constant (at maximum lift/drift) evidently varies con
siderably for different forms of section. Rejecting forms that may be considered bad on account of their low maximum, we find: In Report $72(1912-13)$ the fourth, fifth, and sixth sections given in Fig. 1, constants 0.322 , 0.334, a nd 0.334 , respectively. In the same report, \& ii, figures are given of the tests of four aerofoils varied as to bluntness of leading mately 0.4 three best of these each had a constant approximately 0.4. In the same report an aerofoil corres 
ments forming the basis of the plotting given in Fig. 17 ; any such method of investigation is liable to prove delusive. ${ }^{15}$

In the first place each aspect ratio should be explored by a number of determinations using aerofoils of varying camber; secondly, the aerofoil section must not be uniform from end to end, the section must be "graded," or, as it is sometimes expressed, the camber must "wash out" at the extremities. Beyond this not one series must be tried, but some dozen or more. The final "winner" for each aspect ratio is the aerofoil of greatest lift/drift.

In my opinion, in the present unsatisfactory state of things, it is best (so far as the pressure constant is concerned) to assume a uniform value for all values of aspect ratio, say that given as appropriate to aspect ratio $=6$ in Table $\mathrm{V}$. Whether we consider the $\mathrm{Na}$ tional Physical Laboratory result as valid or not, the salient fact is that we have at present no sufficient evidence that there is any change in the pressure constant worth taking into account. Alternatively, we are not going far astray if we assume aerofoil pressures equa to half the pressure on the normal plane, as shown in Fig. 18

The most important fact with which we are immediately concerned in connection with the theory of least resistance is that the total aerofoil resistance for least value is almost constant in respect of velocity; in other words, provided that we design for least resistance, we lnow our traction coefficient in advance; it is virtually a constant, just as though the problem were that of an automobile required to ascend a hill of known gradient -an analogy which comprehends the fact that there is the direct wind resistance or body resistance additional in both cases. This constant is only within control inasmuch as by careful design the effective value of the coefficient of skin friction $\xi$ can be kept down, and a high aspect ratio adopted. Theoretical values of least gliding angle (that is to say, resistance coefficient), tabulated for values of $\xi$ and aspect ratio, are given in Table VI. ${ }^{16}$ It is of some interest to inquire to what extent these results are in agrepment with modern experiment.

TABLE VI.-Least Gliding Angle $\left(=\gamma_{1}\right)$ (Theoretical).

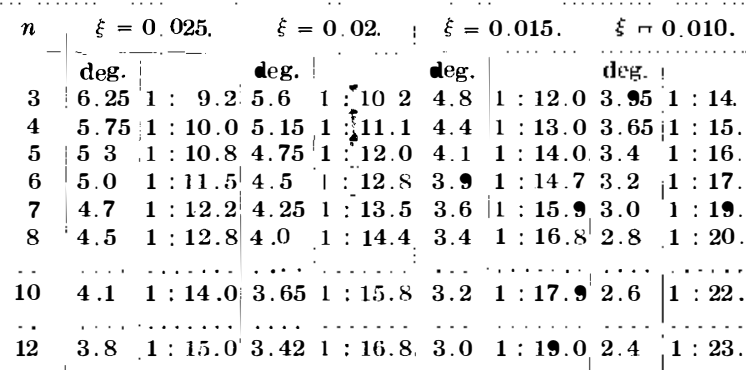

$12 \quad 3.8 \quad 1: 15.0 \quad 3.421: 16.8,3.0 \quad 1: 19.024 \quad 1: 23.9$

I have collected experimental data from various sources; a series of aerofoils of Rlériot section, ${ }^{17}$ aspect ratios vary from 3 to $S$. Determinations of Voisin wing by Mr. Eiffel, aspect ratio 6.3. Aerofoil "R.A.F. 6" (Royal Aircraft Factory), aspect ratio 6. Aerofoils TABLE VII.

\begin{tabular}{|c|c|c|c|c|c|}
\hline 1 & 2 & 3 & 4 & 5 & 6 \\
\hline $\begin{array}{l}\text { Aspect } \\
\text { Ratio. }\end{array}$ & Type. & $\begin{array}{l}\text { Determina- } \\
\text { tion by }\end{array}$ & $\begin{array}{l}\text { Experi- } \\
\text { mental. }\end{array}$ & $\begin{array}{c}\text { Calcu- } \\
\text { lated } \\
\xi=0.02 .\end{array}$ & $\begin{array}{c}\text { Calcu- } \\
\text { lated } \\
\xi=0.015\end{array}$ \\
\hline 3.0 & $\begin{array}{l}\text { Bleriot } \\
\text { section }\end{array}$ & N. P. L. & 10.1 & 10.2 & 012. \\
\hline 4.0 & “ & .. & 11.5 & 11.1 & 13.0 \\
\hline 5.0 & “. & $\ddot{~}$ & $\begin{array}{l}12 . \\
14 .\end{array}$ & & \\
\hline 6.0 & R. A.F. 6 & “. & $\begin{array}{l}14.0 \\
14.5\end{array}$ & 12 & 14.8 \\
\hline $\begin{array}{l}6.0 \\
6.3\end{array}$ & $\begin{array}{l}\text { R. A. F. } 6 \\
\text { Voisin }\end{array}$ & Eiffel & $\begin{array}{l}14.5 \\
14.0\end{array}$ & & \\
\hline $\begin{array}{l}6.3 \\
7.0\end{array}$ & $\begin{array}{l}\text { Voisin } \\
\text { Bleriot } \\
\text { section }\end{array}$ & N. P. L. & 15.1 & 13.5 & 15.9 \\
\hline 8.0 & “" & " & 15.5 & & \\
\hline 10.0 & $\ldots \ldots$ & $\ldots$ & $\cdots$ & & 9 \\
\hline \multirow[t]{2}{*}{12.0} & & & & 16.8 & 19.0 \\
\hline & & & & $\cdots$ & .... \\
\hline \multirow[t]{3}{*}{13.3} & Author, & " $\dagger$ & 20.0 & $\ldots$ & \\
\hline & 1894 & Göttinge & 16.4 & $\ldots$ & $\ldots$ \\
\hline & & “ $\ddagger$ & 17.3 & $\ldots$ & $\cdots$ \\
\hline
\end{tabular}

from my $16: 94$ model, aspect ratio 13.3 , Fig. 16, independent determinations by N.P.L. and Göttingen laboratories. The above are given in Table VII; columns ${ }^{15}$ It is an old axiom that in conducting a scientific research only one condition (when possille) should be changed at a time. In trying to adhere to this rule too literally it is asy to mistake the shadow for the substance; in the present example, to vary the length of an aerofoil of constant section may appear superficially to be "ch

${ }^{16}$ From "Aerial Flight," vol. i, p. 262

${ }^{17}$ Report of the Advisory Committee for Aeronautics, 1911. 1912 , p. 75

Velocity, 30 feet per second.

$\dagger$ Value at 50 feet per second (computed by National hysical Laboratory).

$\ddagger$ Velocity not stated.
1,2 , and 3 give the aspect ratio, type, and authority respectively; column 4 gives the experimental determination, and $\mathrm{my}$ theoretical values are given in columns 5 and 6 for values of $\xi=0.02$ and $\xi=0.015$ Table VII is shown plotted in Fig. 19, the relation of aspect ratio to lift/drift being represented by curves drawn through the observed and calculated values.

It will be noted on referring to Table VII and Fig. 19 that the agreement is almost complete. The two case of the Eiffel determination of the Voisin aerofoil and the "R.A.F. 6" aerofoil are shown as outlying points, not being fully in agreement with the main run of the re maining experimental determination; it will be noted, however, that the whole of the experimental values lie between the two adjacent theoretical curves given, an the general form of the experimental curve correspond to the curves given by my equations. It is true that there is something in the nature of the hump on the experimental curve, the extremities of which corre sponds to a double-surface coefficient of skin friction of 0.02 , whereas the central part of the curve round about aspect ratio $=6$ rises nearly to the upper curve. Thi peculiarity of angular character of the curve may be real feature, but I am disposed to think that it is more probably due to the fact that a great deal more experimental work has been done in the region of the hump of the curve, and so more highly perfected forms have been available than for aspect ratios of greater or les value. It would appear probable that if equal diligence were displayed in designing and testing forms of othe aspect ratios, the upper theoretical curve $(\xi=0.015)$ would be found to be very close to the truth; some confirmation of this is found in the fact that the best value for the "R.A.F. 6" aerofoil, a form that has been subject to considerable study both by the Royal Aircraft Factory and the National Physical Laboratory, lies consid erably above the curve representing the run of other observations.

In the National Physical Laboratory report to me on the tests of my 1894 model, it is stated that if it had been found possible to employ a velocity of 50 foot-seconds instead of 30 foot-seconds, the figure obtained would probably have reached the neighborhood of 20 . This value is also plotted as an outstanding point in Fig. 19.

Summarizing the position, it is clear that the tractive effort required to overcome fiight resistance propernamely, the aerofoil resistance-need not exceed 1 in 12 to 1 in 14, that is, 7 or 8 per cent, using an aspect ratio of about 6 , and that values less than this are to-day actually reached in existing machines. It is, furthermore, apparent that if it is found practicable to employ really high aspect ratio, such as in my early fiight models, there is every reason to suppose that a resistance coefficient as low as 6 per cent, or even 5 per cent, may prove to be attainable. This is the magnitude of the "constant gradient" of the motorcar analogy. We now pass to the consideration of body resistance.

(To be continued.)

\section{(TnTrespandeมre}

[T'he cditors are not responsible for statements made in the correspondence column. Anonymous communications cannot be considered, but the names of corre spondents will be withheld when so desired.]

The Use of Graphite in Steam Boilers To the Editor of the Scientific American Supplement On page 35 of your Scientific American SuppleMENT No. 2011, dated July 18th, 1914, there appears an article, entitled "Graphite Against Furring," wherein it is intimated that the use of graphite in steam boilers as a scale remedy originated in Germany. We beg to inform you that the United States Graphite Company discovered this new use for graphite and were the first to offer it for sale for this purpose. The idea of using graphite as a boiler scale remedy was first brought to our attention by one of the best sugar plants operating in Colorado which experienced a great deal of trouble in this direction, and in casting about for a dependable removing agent secured, through our Denver branch, some of the graphite which we mine in Mexico, and tried it with such excellent result that we then, on our own account, made a great many exhaustive tests in a number of power plants, inclusive of our own here in Saginaw. where the feed water is usually bad.

The results following this investigation were so re markable, and finding Mexican graphite to be, of al graphites, the best physically adapted for this use, we commenced to exploit it in that field with very remarkable success. Unite» States Graphite Company. Saginaw, Mich.

\section{The Horsepower of a Cannon}

A MOdern field gun firing a 15-pound shot with a muzzle velocity of 1,600 feet per second gives it an energy

of $\frac{15}{2}+\cdot \begin{gathered}(1,600)_{2} \\ 32\end{gathered}$ foot pounds. If we assume that the time required is one hundredth of a second, the horsepower developed is

$$
\begin{aligned}
& \frac{15}{2} \times \frac{(1,600)_{2}}{32} \times \frac{100}{33,000} .= \\
& \frac{15 \times 256,000,000}{2 \times 32 \times 5,500}=108,000 \text { h.p. }
\end{aligned}
$$

Ships' guns greatly exceed this, the shot weighing as much as 1,100 pounds, and having a muzzle velocity of 3,000 feet per second. If we assume, as before, that the shot takes one hundredth of a second to reach the muzzle (it probably takes rather longer), we have for the horsepower in this case:

$$
\frac{1,160 \times 9,000,000 \times 100}{2 \times 32 \times 5,500}=28,000,000 \text { h.p. }
$$

WE wish to call attention to the fact that we are in a position to render competent services in every branch of patent or trade-mark work. Our staff is composed of mechanical, electrical and chemical experts, thoroughly trained to prepare and prosecute all patent applications, irrespective of the complex nature of the subject matter involved, or of the specialized, technical, or scientific knowledge required therefor.

We also have associates throughout the world, who assist in the prosecution of patent and trade-mark applications filed in all countries foreign to the United States.

$$
\text { Munn \& Co., }
$$

Patent Solicitors

361 Broadway,

Branch Office

New York, N. Y.

625 F Street, N. W.,

Washington, D. C.

\section{SCIENTIFIC AMERICAN SUPPLEMENT \\ Founded 1876}

NEW YORK, SATURDAY, AUGUST 15, 1914

Published weekly by Munn \& Company, Incorporated

Charles Allen Munn, President; Frederick Converse Beach, all at 361 Broadway, New York
allary

Entered at Post Office of New York, N. Y., as Second Class Matter Copyright 1914 by Munn \& Co., Inc.

The Scientific American Publications

Scientific A merican Supplement (established 1876) per year $\$ 5.00$ Scientific American (established 1845) . . . . “ 3.00 American Homes and Gardens . . . . . . including Canada, will be furnished upon application

Remit by postal or express money order, bank draft or check

Munn \& Co., Inc., 361 Broadway, New York

The purpose of the Supplement is to publish the more important announcements of distin guished technologists, to digest significant articles that appear in European publications, and altogether to reflect the most advanced thought in science and industry throughout the world.

\section{Table of Contents}

Stellar Radiation, Thermo-electric Measurements of.By A. II. Pfund.- 3 illustratio

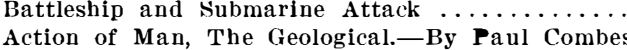

Iron Ore Output of the World

Turbine Reduction Gear, Development of the Westing.

house.- $\rightarrow$ illustrations $\ldots \ldots \ldots \ldots \ldots \ldots \ldots \ldots$
.

Distances of the Planets and Satellites, The Law of. Alcohol from Woo

Dock at St. Thomas, The New Coaling.-By C. T. Mason. ${ }_{\text {Record }}^{7}$ Again Broken, The Altitude

Hydraulic Power Plants, A surge Tank for - 3 il.....

Mars, The Ridle of. -3 illustrations

Safety in Aeroplanes Result of First Contest in Fra..

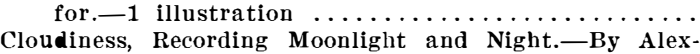
ander McAdie.-4 illustrations

Flying Machine from an Engineering standpoint, The.

II.-By Frederick William Lanchester--10 illus-

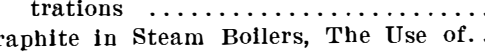

Horse-power of a Cannon, The U. 